\title{
Effect of modified atmosphere packaging (MAP) on physicochemical of fresh-cut bottle gourd
}

\begin{abstract}
The effect of modified atmosphere packaging (MAP) with different initial gas compositions on fresh-cut bottle gourd was determined. Vegetables were packaged under each of the following conditions: (1) $3 \% \mathrm{O} 2 / 9 \% \mathrm{CO} 2$ initially, (2) $5 \% \mathrm{O} 2 / 5 \% \mathrm{CO} 2$ initially and (3) $9 \%$ $\mathrm{O} 2 / 3 \% \mathrm{CO} 2$ initially. Passive modified atmosphere packaging with air inside initially $(20.9 \%$ $\mathrm{O} 2 / 0.03 \% \mathrm{CO} 2$ ) was used as the control treatment. Changes in headspace, weight loss, firmness, colour, $\mathrm{pH}$, soluble solid content, titratable acidity and sensory characteristics were evaluated. $\mathrm{O} 2$ concentration continuously decreased below its initial concentration for all packaging conditions. Meanwhile, $\mathrm{CO} 2$ concentration inside all packages continuously decreased up to $17 \%$ from the initial conditions. The results indicated a minimum reduction in flesh firmness and delayed the change of colour values in packaged 2 and 3. There were no significant differences observed for titratable acidity, $\mathrm{pH}$ and soluble solid content among packaging conditions. In conclusion, the higher oxygen content was effective to maintain the postharvest quality of fresh-cut bottle gourd.
\end{abstract}

Keyword: Modified atmosphere packaging; Physicochemical; Fresh-cut bottle gourd 